Adolescencia e intimidades: narrativas en transición

José María Nava-Preciado

Revista Argentina de Estudios de Juventud, (15), e052, 2021

ISSN 1852-4907 | https://doi.org/10.24215/18524907e052

https://perio.unlp.edu.ar/ojs/index.php/revistadejuventud

FPyCS | Universidad Nacional de La Plata

La Plata | Buenos Aires | Argentina

\title{
ADOLESCENCIA E INTIMIDADES: NARRATIVAS EN TRANSICIÓN
}

\author{
Adolescence and Intimacies: Narratives in Transition
}

José María Nava-Preciado

jnava_preciado@yahoo.com.mx

https://orcid.org/0000-0003-2050-1251

Departamento de Filosofía

Universidad de Guadalajara | México

\section{Resumen}

Palabras clave

El autor explora en este artículo las valoraciones de los/as adolescentes acerca de la intimidad y analiza, a partir de ellas, cómo se configuran y se implican las relaciones

jóvenes urbanos afectivas en la actualidad. Enmarcada en el paradigma interpretativo, la investigación afectividad narrativas intimidad recupera el trabajo de campo realizado mediante grupos de discusión y entrevistas semiestructuradas con estudiantes de escuelas preparatorias de la Zona Metropolitana de Guadalajara, México. Los relatos obtenidos sugieren que las relaciones íntimas se tejen, en gran parte, alrededor de las redes sociales, lo que provoca el ensayo de tramas narrativas que sustituyen los relatos dominantes que durante mucho tiempo se posicionaron como infalibles y como únicos para organizar los modos de vivir las intimidades.

\section{Abstract}

\section{Keywords}

urban youth affectivity narratives intimacy

In this article, the author explores adolescents' assessments of intimacy and analyzes, based on them, how affective relationships are configured and involved today. The research is part of the interpretive paradigm and the recovery of the field work was carried out through discussion groups and semi-structured interviews with students from preparatory schools in the Metropolitan Area of Guadalajara, Mexico. The stories obtained suggest that intimate relationships are woven, to a large extent, around social networks, which provokes the rehearsal of narrative plots that replace the dominant stories that for a long time were positioned as infallible and as unique to organize the modes of live the intimacies. 


\title{
ADOLESCENCIA E INTIMIDADES: NARRATIVAS EN TRANSICIÓN
}

\author{
Por José María Nava-Preciado
}

\section{Introducción}

El contexto de la existencia humana está marcado por pautas que las interacciones sociales construyen cotidianamente. En este marco, en el que cada persona configura sus experiencias vitales, destaca la dimensión íntima. Construir el mundo íntimo implica asumir y vivir aquellas prácticas erótico-afectivas que tienen sentido para el agente. Así, como seres sociales que somos, el sentido de la vida viene dado, en gran parte, por la construcción de la intimidad (Pardo, 1996). Nuestro ser íntimo se constituye mediante la relación dialéctica entre lo público y lo privado (Arendt, 2005), entre la acción y la estructura (Giddens, 1987).

De acuerdo con lo que la experiencia dicta, la construcción de la intimidad inicia en la adolescencia. Si bien es cierto que en esta etapa de la existencia las personas comienzan a fraguar su mundo íntimo, el cual es parte del proyecto de vida y es creado, en cierto modo, siguiendo las narrativas tradicionales, también es cierto que los modelos convencionales definidos por la sociedad como territorios para proyectar la intimidad suelen ser calificados por algunos/as jóvenes/as como pasados de moda y, en algunos casos, vistos como represivos al no responder a las expectativas de los nuevos tiempos.

Frente a esta tradición unitaria, se construyen otras experiencias íntimas que muestran del nuevo rostro de lo social, de esto resulta que la tradición y lo emergente convivan en una clara tensión, donde las concepciones instituidas buscan sostenerse tratando de incorporar aspectos que den cuenta de las apremiantes necesidades de los/as jóvenes. 
Ellos son portadores de valoraciones, de aspiraciones y de discursos sobre la manera de expresar la singularidad de los afectos ante y con los/as demás, que si bien en ocasiones se materializan en relaciones tradicionales como el noviazgo o un matrimonio duradero, en tanto expresión máxima de la relación amorosa, coexisten con otras formas de experimentar la intimidad que día a día emergen y se posicionan en nuestro contexto como es el caso de mostrar los afectos en la web (Sibila, 2012; Walter, 2018).

¿Qué implicaciones tiene esto en la vida cotidiana? El surgimiento de este modo de mostrar la intimidad, principalmente en los/as jóvenes, constituye un indicador de la transición que proyecta el individualismo moderno con relación a aspectos que, sensu stricto, pertenecen a un ámbito de la subjetividad humana que no debiera ser objeto de intrusión por alguien ajeno. En la modernidad tardía, esto se ha vuelto cotidiano y ha cobrado un gran significado para los/as adolescentes (Bohórquez \& Rodríguez, 2014), de tal manera que en la actualidad algunos asuntos salen de casa y se convierten en cuestiones de plaza. Este ánimo por transparentar la intimidad la convierte en algo banal, y lo hace en más de un sentido, debido a que queda expuesta tanto a la vista como a la evaluación y a la calificación de los demás (Livingstone, 2012). El surgimiento de estas formas de mostrar la intimidad implica un proceso de socavamiento de lo instituido que favorece la desinstitucionalización, tal como sostiene Alain Touraine (1997). Se evidencia, así, el debilitamiento o la desaparición de los discursos tradicionales sobre cómo vivir la intimidad.

La intimidad es consustancial a la vida del ser humano, es un vehículo a través del cual se manifiestan los sentimientos, las emociones y las preferencias por algo o por alguien. La intimidad nos inclina a una relación afectiva con el tú, con otro agente que resulta entrañable en la existencia del yo; esa implicación la da sentido al proyecto de vida de ambos. Pero ¿se vulnera el yo en una relación íntima? A ello se puede responder que la relación íntima no es fisura del yo; por el contrario, es un espacio donde este continuamente se encuentra con el tú y, al hacerlo, queda al descubierto la mismidad de cada uno de ellos; así, el tú y el yo forman una unidad que los diferencia y que, al mismo tiempo, los une.

La intimidad también es un descubrimiento del yo, es decir, de una serie de sentimientos y de sensibilidades que antes permanecían ocultos y que se muestran en una relación afectiva como algo extraordinario. Estas sensibilidades, quizás 
antes desconocidas por el propio agente, alcanzan cierta plenitud con el otro; por tanto, en la relación íntima tenemos un yo alterado, tal y como lo sostiene José Luis Pardo (1996). No se trata de un yo pasivo sino de un yo activo, un yo descubierto ante el otro.

El actuar íntimo, en línea con los argumentos de Fernando Escalante (2004), se conforma por aquellas decisiones que quedan fuera de la mirada de los demás, siendo estas confiadas, si el agente así lo decide, solo a unas cuantas personas, mismas a las que se considera como las más cercanas; por ejemplo, la pareja y los/as amigos. De esta manera, cuando se habla de la intimidad en sentido amplio se alude a cuestiones de la vida personal, como las relaciones afectivas, las preferencias sexuales, la filiación partidista, las inclinaciones religiosas, y todo aquello que se deriva de esta serie de prácticas y de experiencias de las cuales no se debe rendir cuentas a nadie. Quizá por esta razón la intimidad sea la parte más sensible de nuestra existencia.

Dado su peso en el imaginario social, la intimidad es abordada desde diferentes perspectivas de análisis. Una breve incursión sobre el estado del arte muestra que los estudios van desde examinar cómo los/as adolescentes y los/as jóvenes han encontrado en la web un espacio par excellence para mostrar sus afectos (Livingstone, 2012; Walter, 2018), hasta los intereses por profundizar, por un lado, en la intimidades femeninas (Lamas, 2017; Luna, 2016; Pavajeau-Delgado, 2018) y, por el otro, en las masculinas (Cruz, 2011). Estas miradas evidencian la trasmutación de las intimidades con el paso del tiempo, pero también cómo los agentes se ven y se piensan a sí mismos, y cuál es su importancia en las relaciones interpersonales.

La intimidad contempla una gama importante de vivencias (Erlebnis), acciones, delicias de los sentidos, pasiones y decisiones que en la vida diaria experimentan las personas. Adultos y jóvenes resuelven, por ejemplo, en qué momento terminar una relación afectiva, definen su preferencia sexual y deciden por qué diversiones optar. Sin embargo, el ámbito de la intimidad no se reduce a esas decisiones tan importantes en la vida de los sujetos, conlleva, también, acciones tan cotidianas como subir a las redes sociales fotografías sobre fiestas o encuentros personales, confiarle a un/a amigo/a algún desencuentro, decidir con quién y dónde vivir; es decir, el campo de elección de un agente en cuanto sujeto 
individual y privado es muy amplio. En ese sentido, dado que cada quien decide qué hacer con su vida íntima, nos podríamos preguntar: ¿por qué es tan capital este dominio en nuestras vidas? Precisamente, porque en él trascurre el diario devenir de nuestra existencia.

Toda persona tiene su vida íntima, lo cual revela el carácter histórico y limitado del concepto, porque refiere a los aspectos más radicales de la subjetividad humana, como lo sugiere Hannah Arendt (2005). Cada etapa histórica emplaza sus propias maneras de vivir la intimidad, por eso se encuentra una multiplicidad de relatos que dan cuenta de los modos de realización afectiva de los agentes en diversas épocas. En los últimos años, sostiene Anthony Giddens (2004), la manera de concebir la intimidad se ha ido transformando y esto se puede contrastar en las narrativas de los/as jóvenes. Sus textos nos posicionan en las mutaciones y en la diversidad de tales experiencias, por eso sostenemos que no es posible aludir a un modelo unitario cuando se abordan las intimidades.

El punto de vista de los/as jóvenes es fundamental para conocer las transiciones que se presentan en la manera en la que se reconstituye el proyecto íntimo en la actualidad; ellos/as son el termómetro de los cambios observables en el modo de sentir la vida. Por esta razón, el objetivo del presente trabajo es explorar las valoraciones de un grupo de adolescentes sobre la intimidad y analizar, a través de su mirada, cómo se llegan a configurar, a legitimar y a implicar las relaciones afectivas. Es decir, lograr un acercamiento a estas experiencias a través de sus propias narrativas juveniles, en tanto elemento estructurante de su concepción del mundo.

Dado lo anterior, es importante aclarar dos cosas: primero, los/as adolescentes quizá no tengan experiencias vivenciales sobre algunos temas. Partimos de este supuesto, por lo cual, más allá de esas limitaciones, interesa obtener pasajes que puedan brindar pistas acerca de las transiciones que están en marcha sobre la forma de concebir la intimidad, desde sus propias valoraciones. Segundo, los/as adolescentes sujetos de este estudio son agentes que viven en el medio urbano; por ello, partimos de la hipótesis de que tienen acceso a Internet, es decir, están incitados e inclinados al dinamismo de las redes sociales, que son parte fundamental de las contextualidades de su vida cotidiana en la escuela, en el barrio, en el hogar, etcétera. 
Desde esta perspectiva, el presente artículo se postula como una manera específica de conocer a los/as adolescentes mediante la cual se busca coadyuvar a formar sobre ellos/as un criterio más amplio e integral, algo que el contexto actual demanda, porque no pareciera advertirse, como apunta James Coleman (2008), que los/as adolescentes tengan un sistema de valores diferentes al del mundo adulto.

Asimismo, conviene señalar que cuando se habla de intimidad se hace referencia a sentimientos y a tratos afectivos que son, fundamentalmente, de carácter eróticoamoroso y de carácter amistoso. El presente trabajo solo se enfoca en los primeros y tiene como guía las siguientes preguntas de investigación: ¿cómo valoran los/as adolescentes, desde sus propios/as referentes, la intimidad? ¿Se apegan a los roles tradicionales de concebirla? O bien, ¿está presente en sus narrativas una transición que emerge de manera significativa?

\section{Entorno teórico}

La noción de intimidad puede ser estudiada desde diferentes ámbitos disciplinares como la sociología, el derecho, la antropología y la psicología social, entre otros. Esto significa que nuestra categoría comprende diversas expresiones y énfasis como pueden ser lo sexual, las relaciones interpersonales, la injerencia del Estado sobre los ciudadanos (Luna, 2016) y hasta su regulación en el ámbito jurídico.

A los fines del presente escrito, la mirada se construye desde una perspectiva sociológica de la vida cotidiana, en línea con la propuesta argumentativa de Giddens (2004), sin dejar de admitir que, dada su naturaleza, se trata de una noción que desborda el análisis disciplinario y requiere de ser comprendida de manera transdisciplinar. Giddens (2004) analiza la intimidad como parte del mundo de vida (Lebeswelt) de las personas; a través de ella los actores, en ciertos micro contextos, se presentan y se proyectan ante los demás. Si bien la intimidad obedece a las acciones de los individuos, no podemos dejar de lado que al ser parte de las relaciones con los otros (Berger, Luckmann \& Zuleta, 1968) se convierte en un asunto de la vida social. Querámoslo o no, está abierta a la mirada de los demás.

Para Giddens (2004), las intimidades se han transformado. ¿Qué podemos entender por eso? Significa que las maneras de expresarla y de resignificarla son distintas en nuestro momento actual respecto del sentido que tenían para generaciones 
anteriores. En cada momento histórico, la intimidad adquiere diferentes tintes significativos. En la actualidad, por ejemplo, la virginidad tiene entre las jóvenes un sentido muy diferente al que tenía para las mujeres de la primera mitad del siglo XX. Desde luego, los factores que intervienen para estas trasmutaciones son diversos. La explosión de las redes sociales y los roles de las mujeres en nuestras sociedades contemporáneas constituyen variables que explican estas alteraciones. Por otra parte, en la actualidad, las manifestaciones sobre las intimidades también son plurales (Giddens, 2004). Los agentes encuentran diferentes vehículos para expresar sus afectividades y su vida erótica con cierta libertad. Sin dejar de reconocer que estas expresiones a veces no son aceptadas por ciertos grupos, es claro que las vivencias íntimas constituyen un rasgo transformador de las sociedades posmodernas.

\section{Entorno metodológico}

La propuesta epistemológica de Gustavo Bueno (1972) es un marco adecuado para situar las características del presente estudio. Este filósofo español arguye que la investigación en las ciencias humanas parte de una metodología beta-operatoria, porque el sujeto que analiza determinado fenómeno está implicado en su operación. Sin embargo, una de las tareas del científico social es alcanzar la objetividad que se materializa en la teoría, lo que genera un regressus, característica esta de una metodología alfa-operatoria, en la cual se eliminan las operaciones iniciales de la primera fase, es decir, toda subjetividad. No obstante, una vez que se llega a categorizar se debe volver a los fenómenos, dándose así un progressus. De esta manera, se genera la dialéctica entre estas dos metodologías que lo que favorece el avance del desarrollo científico en las ciencias humanas.

\section{Hipótesis de trabajo}

Las narrativas de los/as adolescentes sobre la intimidad constituyen un claro ejemplo de las rupturas tradicionales de experimentar y de vivir las intimidades, lo que hace pensar que la sociedad actual transita hacia la definición de narrativas emergentes con nuevos significados en su vida afectiva. 


\section{Técnica y procedimiento para recuperar la información}

Por la naturaleza y los objetivos de la investigación, la recuperación del trabajo de campo se hizo sobre la base de los grupos de discusión y de las entrevistas semiestructuradas. Como se ha mencionado, interesa la narrativa adolescente sobre las coordenadas erótico-afectivas, de allí que el grupo de discusión se presente como una técnica pertinente, en virtud de que provoca un espacio de conversación espontánea y grupal (Llopis, 2004) semejante al de la vida cotidiana (Flick, 2007) cuando se aborda determinada información. En el grupo se busca llegar a ciertos consensos o disensos sobre los temas en discusión.

\footnotetext{
Las hablas individuales confluyen en el grupo tendiendo al consenso o a la disparidad razonada. A través de estos elementos, se produce la elaboración y la construcción-reconstrucción del discurso. El resultado es un material común en torno al tópico que se explora, que contiene los significados sociales (intersubjetivos) que el propio grupo elabora (Suárez, 2005 p. 33).
}

Las entrevistas semiestructuradas, en tanto, ayudaron a obtener respuestas sobre el tema en los términos, en el lenguaje y desde la perspectiva de los/as entrevistados/as, tal y como lo recomiendan Roberto Hernández, Carlos Fernández y Pilar Baptista (2014).

En total, se realizaron cinco grupos de discusión con estudiantes de cinco planteles de escuelas preparatorias de la Zona Metropolitana de la ciudad de Guadalajara, México, cuya edad promedio oscilaba entre los 15 y los 16 años. Cada grupo se formó con ocho adolescentes; dos se integraron por varones, dos por mujeres y uno mixto, con el fin de analizar entre los grupos patrones de coincidencias y de diferencias respecto de las coordenadas de estudio. Con este patrón, se realizaron cinco entrevistas, dos con mujeres y tres con hombres; el trabajo de campo completo se realizó en el mes de noviembre de 2018. Como se constata, a través de estas técnicas se buscó dar voz a los/as investigados, con el fin de intentar comprender sus mundos sociales, una de las tareas de la investigación social (Ragin, 2007).

La operación, esto es, el análisis y la síntesis de los datos, se formalizó mediante el establecimiento de relaciones entre las términos singulares mencionados por los/as adolescentes y las categorías que surgen a partir de la asociación de dichas 
menciones, en las cuales es posible anudar las narrativas. En términos epistemológicos, esto supone ir del dato a la teoría y de esta volver al dato para alcanzar, en este caso, una plena comprensión de los sentidos y los significados que los/as adolescentes le dan a la intimidad.

De esta manera, todas aquellas descripciones o conjunto de expresiones vertidas por estos/as adolescentes, que de acuerdo a nuestro criterio guardan ciertas propiedades semánticas, se agruparon en ítems que dieron origen a categorías [Figura 1] que se comprenden en el marco reflexivo propuesto por Giddens (2004) sobre la intimidad y sus transformaciones en la sociedad actual. Así, cada categoría da cuenta de la singularidad de cierto tipo de expresiones lingüísticas, sin que por ello sean concluyentes. Finalmente, para tener una comprensión más cabal de los fenómenos semánticos, se recuperan textos significativos de los/as adolescentes entrevistados/as, que a modo de colección de casos (Flick, 2007) ilustran la situación contextual y las secuencias seguidas en las conversaciones.

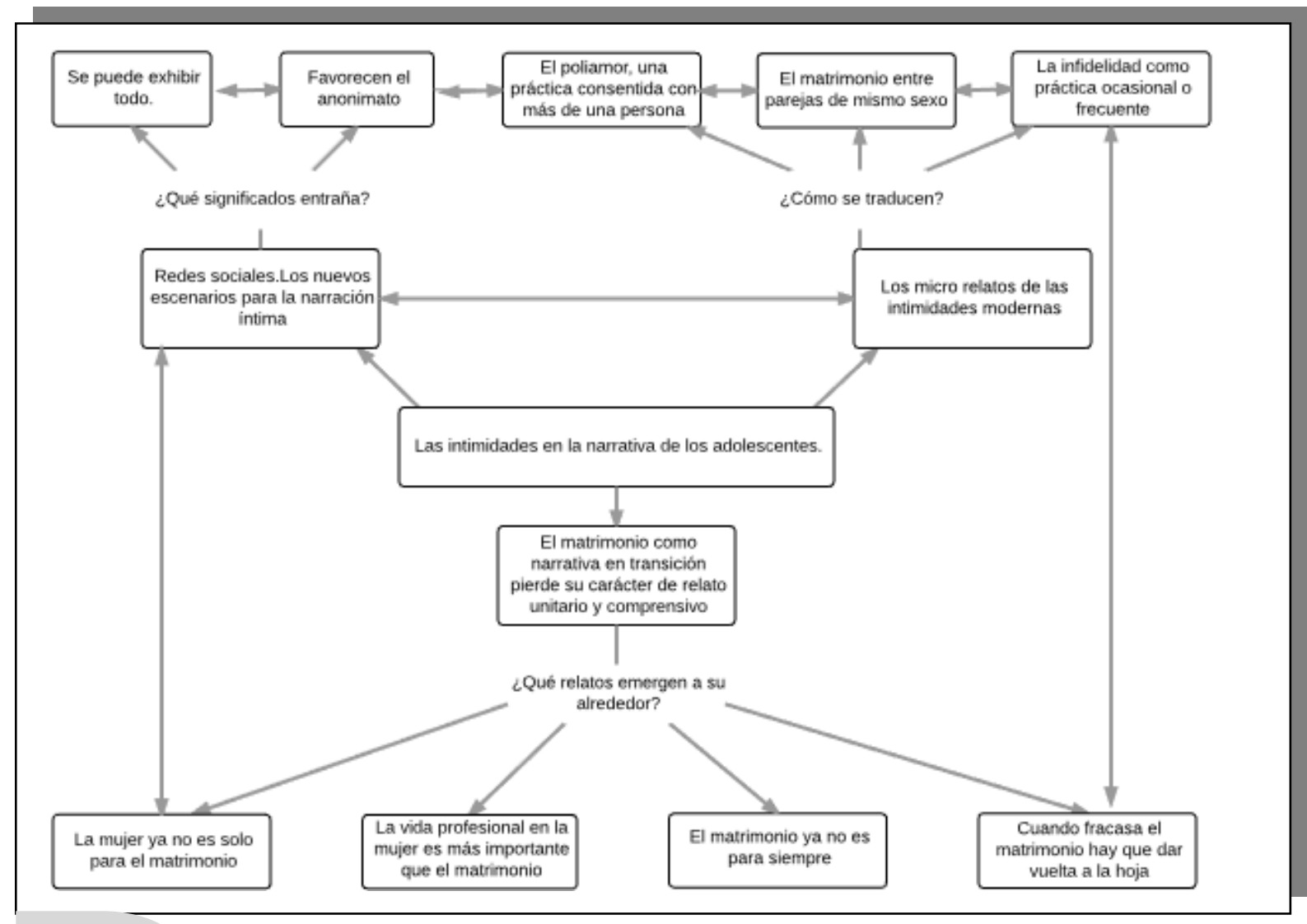

Figura 1 | Construcción de categorías. Fuente: elaboración propia 


\section{Resultados}

\section{Redes sociales: el nuevo escenario para la narración íntima}

La web convoca a las personas a mostrarse, como lo sugiere Paula Sibila (2012). Los/as adolescentes no escapan a esa dinámica, siendo, quizás, quienes con mayor énfasis hacen realidad la idea de que en la web todo se puede exhibir y todo se puede ver.

En las redes sociales se manifiesta nítidamente la consistencia de una nueva alegoría para proyectar la intimidad, especialmente en los/as jóvenes. En la actualidad, lo que vale es exhibir en las páginas electrónicas los asuntos de la vida íntima. Al respecto, surge la pregunta: ¿qué motivaciones provocan la inclinación a proyectar estos asuntos en las redes sociales? De acuerdo con las respuestas de los/as adolescentes, por dos razones: porque favorece el anonimato y porque se puede exhibir todo.

Sobre el primer punto, destacan posturas como las siguientes:

$\mathrm{H}$ : Te puedes enamorar de alguien que no existe.

$\mathrm{H}$ : Si te da pena hablar directamente con la persona,

le mandas un mensaje por WhatsApp o Facebook, y esas cosas...

M: Empiezan a hablar por las redes sociales porque les da miedo hablar con la otra persona, les da miedo que los critiquen.

$\mathrm{M}$ : A veces, hablar por las redes te puede dar un poco de confianza.

M: Hay personas que se expresan mejor por las redes que de frente.

$\mathrm{H}$ : Haces eso porque no te animas a tratar con la persona.

M: Te da más seguridad porque puedes decirle algo y no ves su reacción; en cambio, si ves a las personas observas todas sus expresiones.

(Grupos de discusión, noviembre de 2018)

Estas expresiones enfatizan la seguridad del anonimato para manifestar afectos sin estar pendiente de la mirada del otro, lo que entraña una dicotomía: por un lado, los/as jóvenes/as exhiben públicamente el afecto, pero, por el otro, no quieren ser vistos. El anonimato va aparejado de esta otra mentalidad: en las redes todo se puede exhibir, porque a diferencia de lo que sucede con otros medios, ofrecen la posibilidad de mostrar cualquier experiencia afectiva. 
H: Hay unas personas que quieren publicar todo.

$\mathrm{H}$ : Todo lo que les pasa lo publican. Cuando se pelean con alguien y dicen: «Es un hijo de p@?!\;\$/». Me estresan esas parejas.

M: Una vez vi una foto de una chava abrazada en una cama con un chavo desnudo, pero no se veía nada.

M: No hay problema, pero hay algunos que a todo, todo, todo, quieren tomarle foto y subirla. Hay momentos en los que sí, tomas una foto y la compartes, pero hay momentos en los que estás tan a gusto que no necesitas compartirlo y solo te diviertes.

M: Lo que sucede es que ahí puedes subir todo, todo lo que te pasa. M: Hay personas que no tienen vida porque se la pasan tomándose fotos en las que salgan bien para Instagram.

E: Y cuando ustedes suben fotos, ¿les gusta que alguien les ponga like?

M: Sí, obvio. Es como tu estatus social. Si tienes like eres popular, si no vales cacahuates.

H: Sí. Hay mucha gente a la que le gusta como aprobación.

(Grupos de discusión, noviembre de 2018)

La vida íntima transcurre en el mundo de lo ordinario, quizá por esa razón los/as adolescentes ven como «normal» que las experiencias afectivas cotidianas se exhiban sin pudor, o bien que sus pares lo hagan. Para ellos/as, exponer todo a la mirada ajena y considerarlo como «normal» son dos cosas que van de la mano. En este orden de ideas, las redes se utilizan para que los/as demás sepan de esas experiencias, sean o no trascendentes, sean o no superficiales. Para ellos/as, exhibir los afectos en las redes es parte de una normal vida cotidiana:

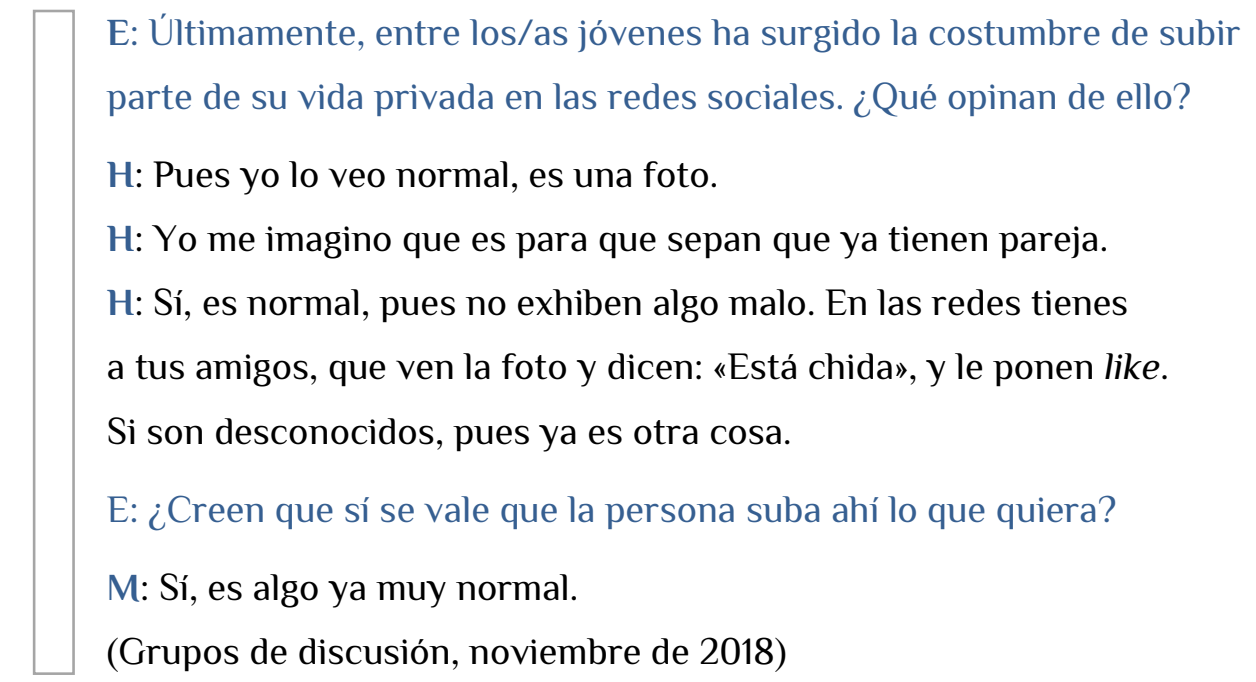


En esa normalidad de exponer las cosas íntimas ante la mirada ajena -de manera un tanto desmesurada si se compara con la forma de constituir y de expresar la intimidad de quienes no crecieron con el auge del Internet y de las redes sociales-, se descubre que, según los hombres entrevistados, se trata de una inclinación más presente en las mujeres (aunque también ellas aceptan ese punto de vista).

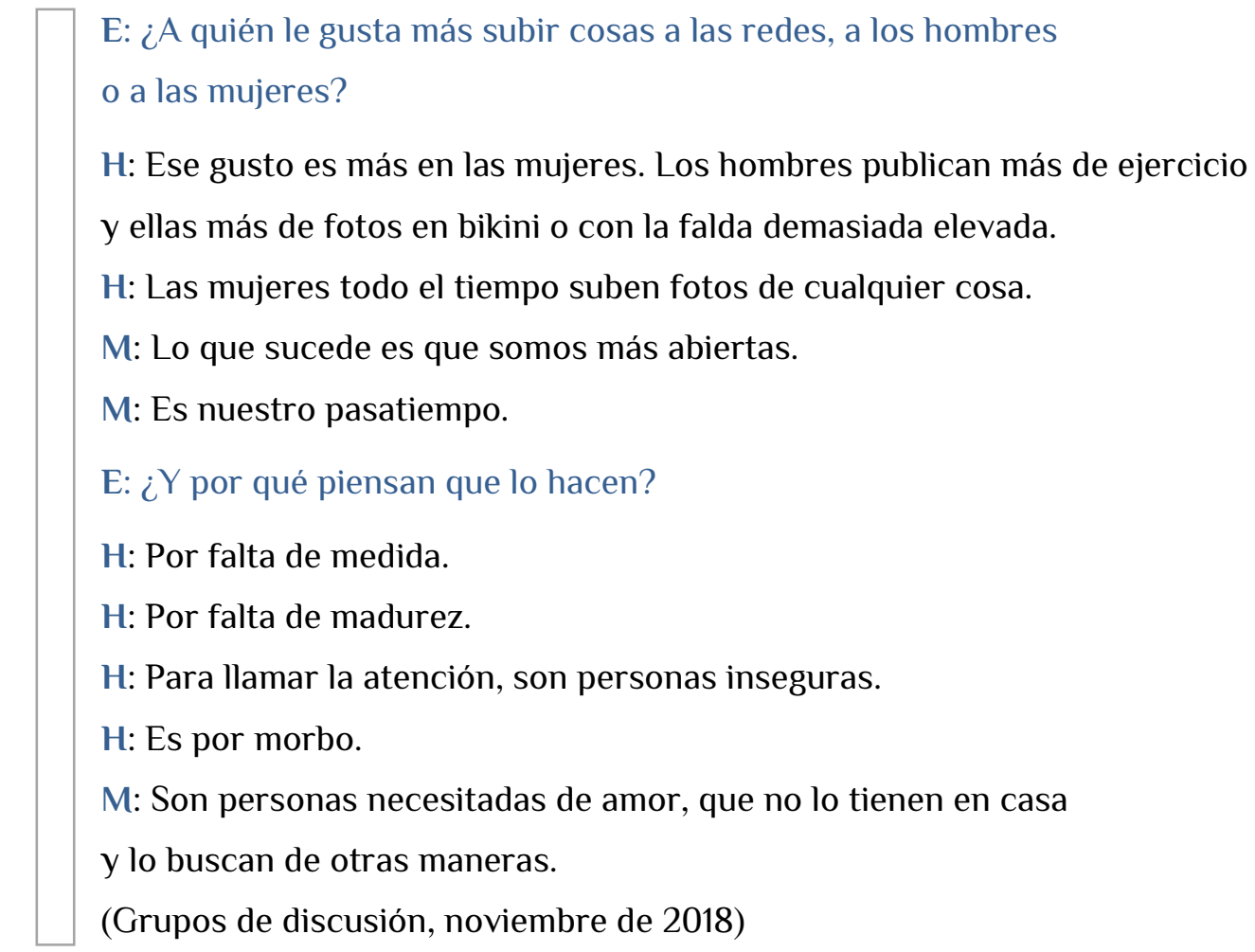

El hecho de que las mujeres sean más propensas a utilizar las redes para mostrar sus afectos no significa que esta práctica sea bien vista. Las redes sociales provocan entre los/as adolescentes, con sus grados y sus matices, valoraciones positivas y negativas; por un lado, existe la aprobación hacia esa práctica; por el otro, reconocen que las relaciones íntimas que se construyen a través de ellas no son de fiar. Para los/as entrevistados, la experiencia es valorada como una moda.

M: Tiene su lado bueno y su lado malo. Hay muchas personas que se han conocido por las redes y han tenido éxito, y hay otras que no. M: Es una moda, pero se me hace una tontería. Es mejor enamorarte de alguien que puedes ver y no de una pantalla o un teléfono. H: Muchas personas lo hacen porque no se sienten seguras de sí mismas y esa es la mejor forma para encontrar una pareja que sea igual a ellos/as. (Entrevistas semiestructuradas, noviembre de 2018) 
Las locuciones de los/as adolescentes muestran con singularidad por dónde transitan las alegorías de la intimidad. La tendencia actual es expresar los afectos ante la mirada de todos/as; por eso, valiéndose de las redes, se publican fotografías, selfies y pequeñas narrativas (por ejemplo, el estado de Facebook) sobre cuestiones que guardan cierto valor personal y que se exhiben con la intención de mostrarse agradable a las miradas de los/as demás. En Internet miramos y nos miran, afirma Gustavo Ariel Kaufman (2015).

Como algunos/as adolescentes sostienen, las personas se «sienten bien» si sus contactos le ponen un like a todo aquello que se expresa sin pudor. En esta red quedan atrapadas las fiestas familiares, el paseo con los amigos, los desencuentros, los recuerdos, el abrazo con la pareja y otros pequeños secretos. Los agentes cuentan aquellos asuntos que son de su interés, pero que no necesariamente son de gran importancia. En muchas ocasiones, resultan ser pasajes de lo intrascendente y lo superfluo. Estamos ante nuevas narrativas en las que se hace a un lado la biografía tradicional y la historia de vida de las personas en favor de la insignificancia de los breves relatos digitales. ¿La razón? Porque se cuenta aquello que no cuenta, lo cual es un reflejo de las condiciones de la rapidez y la incertidumbre de los nuevos sucesos a los que se enfrenta la vida moderna (Bauman, 2006).

Lo explicado hasta aquí deviene, sin duda, en algo paradójico: por un lado, la sociedad actual lucha por darle su lugar a la intimidad, buscando reservarla de la mirada ajena, dada su condición de secreto, como expone Georg Simmel (2010); por otro, sin embargo, los/as ciudadanos/as posmodernos la empeñan y la someten al examen de los demás, convirtiéndola en res pública; es decir, en algo que puede dejarse al inclemente escrutinio del ojo ajeno. Así, la intimidad en las redes sociales se convierte en un interfaz de lo público y lo privado.

\section{Retórica del matrimonio: relato en transición}

En términos históricos, el matrimonio es considerado como uno de los grandes relatos institucionalizados en lo que a la constitución de la familia se refiere. Es una estructura fundamental en la que cada uno de los miembros de la pareja tiene como propósito vivir y desarrollarse, creando un nexo basado en los afectos mutuos, los planes comunes, la regularidad y la consistencia (Hidalgo \& García, 2005). 
Sin embargo, de manera reciente, su figura ha sido sometida a una serie de mutaciones que fracturan si no su permanencia la forma esencialista de pensarlo y de formalizarlo, como producto de los cambios culturales, políticos y sociales a los que se confronta la vida cotidiana (Giddens, 2004).

Las relaciones afectivas entre las personas tienen otras posibilidades de materializarse en un contexto en el que resulta imposible someterse a estructuras tradicionales que no responden a las coordenadas de la singularidad de los agentes. Esto se refleja en las expresiones de los/as adolescentes, cuyas posiciones se pueden agrupar de la siguiente manera: a) la mujer ya no es solo para el matrimonio; b) lo profesional es más importante que el matrimonio; c) el matrimonio ya no es para siempre; d) cuando el matrimonio fracasa hay que dar vuelta a la hoja.

\section{a | La mujer ya no es solo para el matrimonio}

En el relato moderno, la mujer no requiere de la presencia de un varón en casa para cumplir algunas expectativas de su vida como querer a alguien y sentirse querida. Esto significa que el matrimonio no es su única meta de vida. Las mujeres cultivan esquemas de pensamiento en los que se reconocen y se asumen de otra manera, buscan ser más autónomas y luchan por sus aspiraciones y logros.

M: Todo es diferente a lo que pasaba antes, son diferentes formas de pensar. Ahora se piensa en una mayor calidad de vida para ti y está bien, porque si estuvieras igual que antes no sería lo mejor. M: Antes sí se daba mucho el matrimonio, pero ahora no. Ahora tú eres feliz haciendo las cosas que te gustan sin casarte, puedes viajar, ir a donde tú quieras.

M: Hay personas que aun teniendo hijos viven en unión libre y no sienten la necesidad de casarse, porque lo que les importa es el amor; mientras que para otros el matrimonio significa una etapa más en la relación. (Entrevistas semiestructuradas, noviembre de 2018)

Los hombres también toman la palabra sobre este punto $\mathrm{y}$, desde una postura conciliatoria con las mujeres, admiten que en los tiempos actuales una mujer no nace para el matrimonio. 
H: Puede que la mujer piense en casarse, pero supón que su marido muere o cosas así ¿cómo va hacer? Debe pensar en sus estudios.

$\mathrm{H}$ : Ahora la mujer debe pensar en ella misma, debe saber qué quiere y no obligarla a casarse.

H: La mujer no necesariamente tiene que casarse, puede ser feliz soltera. (Entrevistas semiestructuradas, noviembre de 2018)

\section{b | Lo profesional es más importante que el matrimonio}

Los hombres están convencidos de que las mujeres deben darle prioridad a su vida profesional. Esta postura puede tener varias lecturas, pero enfatizamos la que se deja traslucir mediante la propia narrativa de los adolescentes: en nuestras sociedades liberales, el varón implícitamente reconoce que la mujer también debe asumir el compromiso con el sostenimiento del hogar, para lo cual deben contar con oportunidades para su formación profesional.

También las mujeres tienen esta mentalidad: antes que el matrimonio está el aseguramiento de un futuro que les permita, entre otras cosas, sortear vicisitudes afectivas, porque los hombres, como sostiene Giddens (2004), han abandonado algunas responsabilidades económicas que en otros tiempos asumían.

\footnotetext{
M: Como mujer, más bien debes pensar en trabajar. Tienes que buscarte una manera de valerte por ti misma y ver qué puedes hacer tú sola para no depender de nadie. Primero sería un trabajo y después el casarte, pero si te casas que te den el derecho de trabajar. Además, el trabajo es una forma de distraerte.
} 
M: Lo que te haga feliz. Si a ti te gusta el trabajo, no tiene caso que te cases, porque puedes llegar a descuidar tu matrimonio. A mí me llama la atención estudiar medicina, pero también me gustaría formar una familia. Sé que va a ser muy complicado, porque la carrera lleva tiempo, unos once años. Entonces, no puedo ser mamá hasta los treinta y ahí te tenés que poner a buscar marido porque antes no tenías el tiempo por estar estudiando. (Entrevistas semiestructuradas, noviembre de 2018)

\section{c| El matrimonio no es para siempre}

Las relaciones íntimas están hechas de tiempo y los/as enamorados/as lo saben: tiempo para conocerse, para vivir juntos o para decidir terminar la relación. Por eso, puede afirmarse que el tiempo es un factor determinante en las relaciones de pareja: se encarga de que estas maduren, permanezcan o se desgasten hasta su disolución.

Antaño, las parejas pensaban que poner fin a una relación era un desastre; actualmente, los/as jóvenes no están dispuestos/as a darse el tiempo para pensarlo. Los/as enamorados no tienen la prestancia para buscar soluciones o remedios a sus problemas sentimentales: así como deciden juntarse para experimentar el amor, también fácilmente resuelven terminar la relación, sin que esto genere mayor remordimiento. Por eso, para los/as jóvenes el matrimonio ya no entraña la idea de «hasta que la muerte los separe».

H: El matrimonio es solo un papel.

H: El matrimonio es más que un lujo, no se necesita casar uno.

E: Pero si después de varios años de vivir juntos se dan cuenta de que no era el amor de su vida, ¿se divorciarían?

H: Pues sí, porque no tiene caso seguir así.

M: Si empieza a haber problemas, sí.

M: Las familias de antes eran de «pues ya me casé, no tengo vuelta atrás». Luego sucede que sufre de violencia en su casa y se lo calla. Lo mejor es que cada quien esté en su lado, sin llegar a esos extremos.

$\mathrm{H}$ : No estoy de acuerdo con que el matrimonio sea para toda la vida, porque después de muchos años puede que surjan los problemas.

$\mathrm{H}$ : Es mejor retirarse con dignidad y cada quien por su lado.

H: Como se dice: «Los tiempos cambian y los matrimonios no duran». (Grupos de discusión, noviembre de 2018) 
Esta narrativa permite llegar al siguiente supuesto: los/as adolescentes consideran que el matrimonio no debe ser una trampa que convierta a los/as amantes en personas solitarias y amargadas de por vida; si no se cultiva como un relato para la realización personal pierde su sentido en el proyecto íntimo de los agentes. «¿Y si ya no hay amor, para qué mantener la ficción, las cargas y las exigencias?»(ComteSponville, 1996, p. 36), es una pregunta que surge de manera inevitable cuando los/as amantes descubren que el amor llegó a su final. Se produce, así, la transición de la narrativa tradicional sobre el matrimonio hacia una nueva forma de pensarse.

\section{d | Cuando el matrimonio fracasa, hay que dar vuelta la hoja}

Los relaciones afectivas de los/as jóvenes tienen el sello de lo momentáneo. Se disfrutan intensamente, pero están sujetas a ciertas condiciones, como las crisis personales y las expectativas truncadas. Con cierta pericia, dan vuelta las páginas amorosas del libro de su vida, sin que el adiós entrañe propiamente dolor; en algunos casos, incluso, significa la liberación. Sus prácticas íntimas parecen haber interiorizado la ley del cambio enunciada por Heráclito.

E: ¿Si el matrimonio ya agotó todo los medios para mejorar la relación, la pareja debe separarse?

M: En cualquier caso, si a ti te cansó una relación se puede terminar, porque puede que te hayas casado a los dieciocho y se acabe a los veinte y que vuelvas a tener otra relación. Es como... Sí, se puede tener más. $\mathrm{H}$ : Si hay complicaciones, es mejor terminar la relación y buscarse otra. H: Sí, lo que no funciona, mejor terminarlo y ya, para qué aferrarse. $\mathrm{H}$ : Como dicen, hay que dar vuelta la hoja.

M: La Biblia dice que está mal, porque tú te casas con una persona... Por ejemplo, mi mamá cuando se casó con mi papá iba bien hasta los cinco años. En esos años, mi mamá le estuvo aguantando muchas cosas a mi papá hasta que terminó la relación. A mí me decían que eso era pecado, «tus papás se van a ir al infierno", pero yo siento que fue decisión de mis papás. Intentaron arreglar las cosas, no se dio y está bien cada quien por su lado. M: Todos merecemos una segunda oportunidad.

$\mathrm{H}$ : O una tercera.

M: Las que necesites hasta encontrar a la persona.

(Grupos de discusión, noviembre de 2018) 
Las perspectivas manifestadas por los/as entrevistados dejan entrever que las relaciones íntimas transitan por caminos diferentes: en la actualidad, muchos/as jóvenes no conciben estar en condiciones de atar su vida a una relación afectiva para siempre. Esta condición se hace más evidente en las mujeres, quienes, tradicionalmente obligadas a mantener una intimidad pasiva, «han preparado el camino para la expansión del área de la intimidad en su papel de revolucionarias emocionales de la modernidad»(Giddens, 2004, p. 121).

Aunado a lo anterior, en el mundo moderno las relaciones también mutan, por eso es posible encontrar que ciertas entelequias como el matrimonio y la fidelidad son insostenibles. Para estos/as infractores/as, instituciones como el matrimonio, el noviazgo y el amor no tienen ningún valor, y la tradición las ha convertido en cosas (Alberoni, 1991).

La intimidad no se vive de igual manera que en décadas anteriores y cada vez es más manifiesto el interés personal por vivir una vida acorde a un propósito individual y no mutuo. En el pasado, el matrimonio, como unión de las almas (Ranum, 1989) y como figura central en el origen de la familia, no podía concebirse como algo pasajero. El casamiento era para toda la vida, era una experiencia singular, única y en ocasiones irrepetible, y las consecuencias de la separación hacían que la relación se mantuviera a pesar de haberse perdido el propósito de coincidencia.

El presente instaura una narrativa emocional abierta y mutante que simboliza una nueva trayectoria para la condición humana, pues ya no hay temor a las consecuencias que implica su rompimiento. Así, el discurso del matrimonio, como relato predominante, pierde su sentido y su unicidad centralizadas en la visión masculina, en el cual la mujer al comprometerse anulaba su proyecto de vida.

\section{Conclusiones}

Las narrativas de los/as adolescentes sugieren dos consideraciones acerca de la naturaleza de la intimidad, las cuales se presentan con cautela. La primera es que la vida íntima no es algo fijo, no está anclada a un modelo determinado que resulta inmóvil. Por el contrario, al referirse al ámbito de las sensibilidades y las emociones más entrañables, la intimidad deja entrever nuestra condición como seres humanos, 
siendo la indeterminación una de sus características. Esta naturaleza permite suponer que la intimidad es algo enigmático y que no puede ser de otro modo, porque, como señala Octavio Paz (2001), si la persona humana es en sí misma un misterio, su vida íntima será un reflejo de ello. Tal es la razón que nos conduce a sostener que la metáfora final de toda persona es su intimidad.

La segunda consideración permite destacar que en el proyecto íntimo se muestra nuestra fragilidad como seres humanos (Pardo, 1996), pues ella implica abrirnos enteramente a la otra persona. La naturaleza misma de la intimidad conduce al/la otro/a a saber cómo somos; las debilidades y las fortalezas salen a flote (Paz, 2001). Se puede afirmar que las relaciones íntimas no son otra cosa que una revelación de la profundidad de nuestra subjetividad. En este sentido, la intimidad como proyecto de vida transcurre entre el continuum de la fragilidad y la indeterminación, sean cuales sean las formas específicas de su manifestación.

Dado lo anterior, preguntémonos: ¿cómo podemos calificar, si es posible hacerlo, la intimidad en la actualidad a partir de recuperar las voces de los/as adolescentes entrevistados/as? Quizá no resulte exagerado sostener que la intimidad, en los tiempos actuales, se muestra con un alto nivel de sensibilización en, al menos, dos sentidos: por un lado, los/as jóvenes defienden con fuerza su derecho a proteger y a vivir su intimidad, según su propia forma de percibir lo que es más apropiado y de desechar los moldes tradicionales por los cuales los/as adultos/as hemos desfilado; por el otro, y paradójicamente, la intimidad de nuestros/as adolescentes es sensible a la mirada externa, porque ahora los/as demás, adolescentes y adultos/as, están al pendiente de cómo se vive, gracias al fuerte impacto de las redes sociales. Así, nos encontramos con una intimidad asediada por dos flancos: los propios agentes adolescentes y los/as otros/as.

Los relatos adolescentes sugieren que las relaciones íntimas y las concepciones que de ellas se tienen en los tiempos modernos tienen como eje las redes sociales, que para muchos/as jóvenes se han instituido como el núcleo mediador de las relaciones afectivas. En ellas se ha encontrado una manera fácil y expedita de mostrarse a los/as demás, de determinar en qué momento se inaugura una relación o bien cuándo se clausura. A través de las redes puede surgir una invitación a salir y se reitera el afecto, pero cuando brota el desencuentro también se aprovecha este medio para ridiculizar y para exponer al contacto o, simplemente, para borrarlo. 
Para muchas personas, las redes se constituyen en el gran meta relato para instaurar y para clausurar, de manera fácil, relaciones erótico afectivas; esto es, en el medio ideal para la constitución y el ejercicio de las intimidades. Conviene anotar, como argumenta Zygmunt Bauman (2006), que la sociedad contemporánea, dada su precariedad, provoca condiciones de incertidumbre. Se puede decir que los agentes modernos con dificultad pueden precisar qué defienden y qué quieren en un mundo cada vez más incierto: por un lado, se busca la seguridad pero, por el otro, cuando se consigue la dejan ir por la borda.

Esta dimensión ambivalente se refleja en los relatos de los/as adolescentes quienes, al igual que el resto de la sociedad, defienden con empeño aquello que no debe ser visto, al tiempo que, paradójicamente, el individualismo moderno los invita a no ser opacos en materia de afectos. Tienen una necesidad emocional de someter a la mirada ajena una serie de experiencias afectivas que para tener sentido se deben transparentar, pudiendo llegar esa transparencia a extremos no deseados; una inclinación que también se asume como una expresión de la originalidad y del espíritu crítico del yo (Carbajo Núñez, 2012).

Ahora bien, las narrativas adolescentes ayudan a comprender por qué las personas no se implican para toda la vida y, con relativa facilidad - salvo casos de excepción-, por qué los/as íntimos/as contemporáneos/as terminan con una relación. Estamos ante una trama en la que muchos/as enamorados/as se encuentran en la constante búsqueda de relaciones afectivas que oscilan entre la ilusión de ver si ahora sí es posible y la predisposición para olvidar y para experimentar nuevos afectos bajo el ritmo de la rapidez. En este tipo de relaciones, recuperando una sentencia de André Comte-Sponville (1996), el olvido y la inconstancia son la norma.

De esta manera, se observa cómo en nuestra vida cotidiana las relaciones afectivas duraderas han agotado su confianza. Los agentes saben que los compromisos asumidos por unos y por otros son precarios; sobre todo, cuando revelan que de acuerdo a las expectativas de uno de ellos el otro no es capaz de entregarse. Descubrirlo es suficiente para terminar la relación afectiva, y cuando esto sucede se está listo para experimentar y para construir nuevos afectos.

Hombres y mujeres están dispuestos/as a ensayar otras formas de experimentar la singularidad de las intimidades, con nuevos tiempos y nuevas intensidades, como 
lo relatan los/as adolescentes, y sin que ello signifique atarse por mucho tiempo a una relación erótico-afectiva. Esto no implica una generalización, porque quizá estas transiciones no se vivan de la misma manera en los diferentes grupos sociales, subculturas y regiones del país. Sin embargo, la experiencia muestra que en los espacios urbanos donde se encuentran concentrados los mayores núcleos de población los/as jóvenes se amparan en la sombra del anonimato y del encuentro episódico para experimentar la explosividad de estas transiciones.

En todo caso, lo importante es que mediante la narrativa adolescente podemos descubrir cómo se escrituran y se textualizan formas subversivas y distintivas de expresar las intimidades modernas, tal y como lo esgrime a Giddens (2004), lo cual refleja, por una parte, la estructura dinámica de la esfera subjetiva y, por la otra, los códigos que el yo comparte con el otro. Por supuesto, sería absurdo pensar que las intimidades tienen un solo código; nuestra sensibilidad humana busca de manera permanente nuevas escrituras para materializar los afectos hacia los demás. Particularmente en la actualidad, el contexto cultural y político, eminentemente mediatizado y mediado por el consumo, provoca el ensayo de tramas narrativas que sustituyen -en muchos casos, de manera contundente- los relatos dominantes que durante mucho tiempo se posicionaron como infalibles y únicos.

Finalmente, es posible que se cuestionen las reflexiones realizadas en este trabajo sobre las valoraciones que los/as adolescentes tienen acerca de la intimidad, pues no todos los/as jóvenes la viven de la misma manera, lo cual es muy cierto. Lo importante es aceptar que nuestras adolescencias urbanas viven en un contexto cultural y social que determina, en gran parte, sus proyecciones afectivas. Esta es una premisa que no se puede dejar de lado. Los estímulos erótico-afectivos están en cualquier parte, y quizá por esto se comprenden muchos de los significados cuando los/as adolescentes despiertan al mundo de las intimidades.

De igual manera, debemos decir que las posturas de estos/as jóvenes sobre los diversos puntos alrededor de la vida afectiva no tienen la misma aceptación en todos los casos. En algunos temas, sus respuestas pueden calificarse como difusas, ya que no están lo suficientemente estructuradas, lo que puede explicarse a partir de variables como la edad, factor que determina, en términos generales, las vivencias y las experiencias en algunos asuntos relacionados con la vida erótico-afectiva. 
Sin duda, también influye en sus narrativas la condición de género $y$, particularmente, el contexto familiar, que afecta la totalidad de la existencia de los/as adolescentes, en un momento que resulta propicio para ensayar la configuración de su erotismo emergente. Tampoco se puede dejar de lado que tienen como aliadas a las redes sociales, un elemento fuertemente estructurante del discurso de la vida moderna.

Todo lo anterior, lleva a sostener la importancia de continuar con investigaciones más amplias que permitan plantear un debate en profundidad, a fin de conocer el mundo por el que transitan los/as jóvenes y de encontrar explicaciones a los modelos de racionalidad afectiva, diversos y recombinantes, por los que se encamina la sociedad actual, dispuesta a reinventarse de manera permanente.

\section{Referencias}

Alberoni, F. (1991). Enamoramiento y amor. Ciudad de México, México: Gedisa.

Arendt, H. (2005). La condición humana. Barcelona, España: Paidós.

Bauman, Z. (2006). La vida líquida. Barcelona, España: Paidós.

Berger, P., Luckmann, T. y Zuleta, S. (1968). La construcción social de la realidad. Ciudad Autónoma de Buenos Aires, Argentina: Amorrortu.

Bohórquez, C. y Rodríguez, D. (2014). Percepción de amistad en adolescentes: el papel de las redes sociales. Revista Colombiana de Piscología, 23(2), 325-338. http://dx.doi.org/10.15446/rcp.v23n2.37359

Bueno, G. (1972). Ensayos materialistas. Madrid, España: Taurus.

Carbajo Núñez, M. (2012). El espectáculo de la intimidad. Raíces históricas de la comunicación centrada en el yo. El Ágora USB, 12(2), 449-534. https://doi.org/10.21500/16578031.86 
Coleman, J. (2008). La sociedad adolescente. En J. A Pérez, M. Valdez y M. H. Suárez, (Coords.), Teorías sobre la juventud (pp. 109-167).

Ciudad de México, México: Universidad Nacional Autónoma de México / Porrúa.

Comte-Sponville, A. (1996). Pequeño tratado de las grandes virtudes. Santiago de Chile, Chile: Andrés Bello.

Cruz, S. (2011). Sentido y práctica de la intimidad masculina. Una mirada desde los hombres. Sociológica, 73(26), 183-207. Recuperado de http://www.sociologicamexico.azc.uam.mx/index.php/Sociologica/articl e/view/109

Escalante, F. (2004). El derecho a la privacidad. Cuadernos de transparencia 02. Ciudad de México, México: Instituto Nacional de Transparencia, Acceso a la Información y Protección de Datos Personales (IFAI).

Flick, U. (2007). Introducción a la investigación cualitativa. Madrid, España: Morata.

Giddens, A. (1987). Las nuevas reglas del método sociológico. Crítica de las sociologías interpretativas. Ciudad Autónoma de Buenos Aires, Argentina: Amorrortu.

Giddens, A. (2004). La transformación de la identidad. Madrid, España: Cátedra.

Hernández, R., Fernández, C. y Baptista, P. (2014). Metodología de la investigación. Ciudad de México, México: McGraw-Hill.

Hidalgo, A. y García, R. (2005). Historia de la filosofía. Oviedo, España: Eikasia. 
Kaufman, G. A. (2015). Odium dicta. Libertad de expresión y protección de grupos discriminados en internet. Ciudad de México, México: Consejo Nacional para Prevenir la Discriminación (CONAPRED).

Lamas, M. (2017). Trabajo sexual e intimidad. Cuicuilco Revista de Ciencias Antropológicas, (68), 11-34. Recuperado de https://www.revistas.inah.gob.mx/index.php/cuicuilco/article/view/1 $1288 / 0$

Livingstone, S. (2012). Tomando oportunidades arriscadas na criação de conteúdo jovem: $\mathrm{O}$ uso pelos adolescentes de sites de redes sociais para intimidade, privacidade e expressão própria. Comunicacao, Mídia e Consumo Sao Paulo, 9(25), 91-119. Recuperado de http://revistacmc.espm.br/index.php/revistacmc/article/view/313

Llopis, R. (2004). Grupos de discusión. Madrid, España: ESIC.

Luna, A. (2016). Pensando el trabajo sexual desde una protagonista.

Una visión a las intimidades de una cantina en el sur de Veracruz.

Andamios, 13(30), 195-210.

https://andamios.uacm.edu.mx/index.php/andamios/article/view/8

Pardo, J. L. (1996). La intimidad. Valencia, España: Pre-Textos.

Pavajeau-Delgado, C. (2018). Migración y movilidad académica de mujeres colombianas cualificadas, transnacionalización de los afectos y asuntos de intimidad. Sociedad y Economía, (34), 11-25. https://doi.org/10.25100/sye.v0i34.5646

Paz, O. (2001). La llama doble. Ciudad de México, México: Seix Barral.

Ragin, CH. (2007). La construcción de la investigación social. Bogotá, Colombia: Siglo del Hombre. 
Ranum, O. (1989). Los refugios de la intimidad. En P. Ariés y G. Dubi (Dirs.), Historia de la vida privada (pp. 211-265). Madrid, España: Taurus.

Sibila, P. (2012). La intimidad como espectáculo. Ciudad Autónoma de Buenos Aires, Argentina: Fondo de Cultura Económica.

Suárez, M. (2005). El grupo de discusión. Una herramienta para la investigación cualitativa. Barcelona, España: Laertes.

Simmel, G. (2010). El secreto y las sociedades secretas. Madrid, España: Sequitur.

Touraine, A. (1997). ¿Podremos vivir juntos? Ciudad Autónoma de Buenos Aires, Argentina: Fondo de Cultura Económica.

Walter, J. (2018). Las órbitas de contacto en Facebook. Intimidad, sociabilidad y amistad en adolescentes de sectores populares de Buenos Aires. Comunicación y Sociedad, (32), 171-190.

https://doi.org/10.32870/cys.v0i32.6924 